\title{
How Could Transportation Developments Facilitate Labor Redistribution in China?
}

\author{
Xuanmeng Dong ${ }^{1 *}$, Xiaobo Meng2* \\ ${ }^{1}$ Harbin No. 1 Senior High School, Harbin, China \\ ${ }^{2}$ Jinan Foreign Language School, Jinan, China \\ Email: 1907096379@qq.com
}

How to cite this paper: Dong, X.M. and Meng, X.B. (2019) How Could Transportation Developments Facilitate Labor Redistribution in China? Journal of Human Resource and Sustainability Studies, 7, 475-488.

https://doi.org/10.4236/jhrss.2019.74031

Received: September 16, 2019

Accepted: November 18, 2019

Published: November 21, 2019

Copyright $\odot 2019$ by author(s) and Scientific Research Publishing Inc. This work is licensed under the Creative Commons Attribution International License (CC BY 4.0).

http://creativecommons.org/licenses/by/4.0/

\begin{abstract}
Many cities in China suffer from extremely rapid growth and consequent congestion problems. Simultaneously, other cities are stagnating due to emigration. In this paper, we will use comparisons between cities, and at the national levels respectively, to argue that links between transportation and labor distribution may be related. We argue that transportation development may underlie both problems. Based on previous literature, we provide insights into how transportation can lead to labor redistribution and practical solutions to solve these problems.
\end{abstract}

\section{Keywords}

Applied Economics, Transportation, Labor Migration, Labor Redistribution, China, Case Study

\section{Introduction}

In this paper, we are going to talk about how transportation can facilitate labor redistribution in China and suggest that it might be a feasible solution to the problem of unbalanced labor distribution. To accomplish this goal, we will use case studies, analyze national statistics, and review previous literature in the paper.

It is an interesting tendency that no matter whether countries are rich or not, or developed or not, they prefer to invest in transportation facilities. Recently, the China government has constructed the Tibet railroad, which is the highest altitude railway in the world. Moreover, more astonishing transportation advancements are taking place. Along with those advancements, hazards such as overcrowding and contamination have emerged in the cities with convenient *These are co-first author, sorted by alphabetical order of last name. 
transits. These problems can induce epidemic, education inequality, and infrastructure scarcity in those cities. Nevertheless, in smaller cities, the loss of talents and labors is a perpetuating cycle. Undoubtedly, the emerging problem has already aroused the concerns from the government, citizens, and scientists.

Although there are already discussions about overcrowding in metropolises, our focus is more than merely resolve the problem there. We will also concentrate on how to stimulate the retrograde cities to attract labors and how transportation can play a role in labor emigration. Thus, it will still be an interesting topic to discuss, and tough tasks are waiting ahead.

To find the solutions to the problems that we've mentioned above, we suggest that there might be a causal relationship between transportation and labor distribution. In the paper, we will discuss on the city level and the national level, respectively. By comparing the transportation and the population in the two cities, we can assume that the development of transportation can affect labor density. Next, we will reveal the national effects of transportation. We will compare the maps of transportation distribution, labor density, and labor shift tendencies of China to further develop our statement. Indeed, other factors may also contribute to the changes in labor distribution. Thus, to eliminate these confounding factors, we will study a city that was destroyed by a natural disaster and shew a fast population recovery along with the reconstruction of the transportation system.

The data suggested that transportation developments and population growth are always consistent when other factors remain relatively the same, and labor shifts to the regions where transportation is better developed. Thus, transportation development is a contributor to the changes in labor distribution in China. These results also help to give suggestions about developing transportation systems such as TOD and the intercity network to help smaller cities to attract labor.

Currently, the study shows some importance in real-world applications and will contribute to three aspects below.

First, the three provinces in Northeast China including Heilongjiang, Jilin, and Liaoning are continuously experiencing the population loss in the recent years, even though the government enacts some policies to retain these talents, it didn't work effectively. According to the estimate from the State Statistical Bureau, the population in Heilongjiang province is one-third of the population of Guangdong province, which possesses almost the same population several decades ago. Thus, we attempt to resolve the problem of talent loss in these provinces, at least retard this trend. By researching this topic, we could point out one of the causes.

Second, as a developing country, China has already reached a population threshold of one billion and four hundred billion people, but it is distributed extremely uneven. Some of the provinces or cities are encountering flagrantly severe overcrowded problems such as pollution, housing problem, etc. What is most astounding is that this trend is still growing. In our research paper, we fo- 
cus on one of the aspects to figure out the potential solution.

Finally, transportation involves in each individual's life. That's part of the reason why we choose this factor as our topic. If there is indeed a relationship between transportation development and the population distribution, some changes in transportation would make gigantic differences to the labor redistribution.

Different from other studies, our paper provides new perspectives and inspirations on the topic of transportation development.

First, even though the government has already enacted policies such as garbage classification policies and subsidies for the low-income population to solve the housing problem, people rarely consider redistributing the population. Our focus on the population redistribution would not only thoroughly resolve overcrowding in the metropolis but also bring new impetus to promote developments in cities that experienced severe talent loss.

Second, our focus is very unique. Transportation development is a factor that involves each citizen in but we barely notice it. If we figure out the relationship between transportation and the population and carry out some substantial changes based on that relationship, the changes would be dramatic.

The paper also has a weakness, albeit reasonable methods are applied. To do more specific research, we exclusively choose two typical cities as our subjects. However, our blemish is that our subject amount is too small. The magnitude of the effects that transportation can have may vary from city to city. Therefore, the relationship shown above may not be universal. Moreover, because there are too many confounding variables in the process of contrasting two cities, and we only include two variables in our research, we cannot promise transportation is the main force that drives labor migration.

Our paper structures as follows: in Chapter 2, we will offer a thorough review of previous studies that discuss the economic effects of transportation systems and population distribution patterns. Then we will use case studies and map comparisons to suggest that a causal relationship between transportation development and labor migration may exist in Chapter 3. Next, we are going to evaluate economy growth brought by the labor migration in Chapter 4 . We will discuss the effects of transportation on labor redistribution in Chapter 5. Finally, in Chapter 6, we will give other solutions and considerations.

\section{Literature Review}

Transportation is a hot topic to debate in many current papers. Most of the previous papers focus on the role of transportation in regional development and economic growth. However, our paper tells a different story about what transportation can contribute to balance labor distribution on a national level. As the inequalities between cities in China become more and more striking, understanding transportation's effect and resolving the unbalanced labor distribution seem increasingly crucial. Under such situations, this paper may hopefully provide inspirations to how transportation can help to promote synchronized re- 
gional growth and fight inequality.

Because our paper mainly concentrates on transportation and labor, discussing the transportation's role in regional development and population distribution can help to lay a solid foundation. Therefore, we examined previous literature that talks about two aspects: the effects on economic growth and the population pattern of China.

To begin with, we reviewed the journals focusing on the effect of transportation on economic growth, both spatially and statistically. In the article written by Stephen J. Redding et al. (2014), they established models to show the cost and spatial effects of transportation development. They concluded that transportation improvements are responsible for the increment in goods costs, wages, and land prices. Moreover, their paper proposed that the transportation system also generates a decentralized pattern of economic activity, including the outflow of the industries in central cities [1]. Other literature paid attention to the spatial effects of transportation, too. In the study done by Ahlfeldt et al. (2012), they studied the effects of transportation by conducting natural experiments on the Berlin Wall, which restrained the transportation connections between the West and East German. By comparing the economic conditions before and after its removal, they concluded that the removal of the Berlin Wall caused the transportation cost to decrease and the business centers to diverge [2].

Statistically, transportation systems can also have a significant effect on economic growth. The transportation system will have a moderately positive effect on the per capita GDP level, and the factor of mobility, including the mobility of capital and goods, contributes to economic benefits significantly. However, the immobility of factors caused by policies restricted a broader extent of growth, which in turn leads to the same measure of growth in both well-connected and poorly-connected regions [3].

We notice that the study assumed that labor is not mobile among regions due to the policy restrictions in China. However, considering that there were above 200 million internal immigrants in China every year since 2010 [4], we can no longer assume the effects on the economy caused by labor migration as insignificant. Therefore, it seems that analyzing the relationship between transportation and labor migration is a topic worth discussing.

As a result, our paper will also build on the previous work about labor migration and population distribution. Chinese population shows a clear distribution pattern, which shows a higher concentration in the southeast and a lower concentration in the middle and northwest part [5]. Also, economic accumulation is more concentrated in densely populated areas. According to the World Bank, the main flows of labor migration in China are the following three: from western to the coastal areas, from central to coastal regions, and among coastal regions where are well-connected and prosperous economically [6].

Our study, built on previous literature about transportation and population, tries to combine these two factors and gives thoughts about how to transportation can lead to the labor redistribution that may result in a more balanced 
growth nationally. We will further provide more evidence on the relationship between transportation and labor migration and potential ways that the improvements in transportation can help to achieve a more balanced labor distribution pattern.

\section{Transportation and Labor Distribution}

The first step to understanding transportation and labor is to find out the relationship between these two factors. Causality might be one of the reasonable relationships that can explain the phenomenon mentioned above.

In this chapter, we will first provide evidence from city-level comparison and then look at the national-level evidence. To eliminate confounding factors, we'll also provide a case study.

\subsection{Methodology}

Undoubtedly, the most straightforward and apparent method is to find two typical cities and carry out the data to figure out the solutions. So we pick up Shenzhen and Harbin because their population and transportation development level remain the same during the 1980s. The comparison between the two cities would provide us with insight and inspiration that would resolve the population redistribution problem.

Second, to observe the phenomena and analyze it from a general aspect, we employed data that include the entire cities in China. These data manifest the population fluctuation in the recent decade and reveal the transportation development level from the aspects of land, air, and waterline transportation.

Third, we include a natural experiment. Hyogo-ken experienced a giant earthquake that destroys the transportation system several decades before, which allowed us to examine the effect of transportation exclusively. Those interesting phenomena occurred afterward further testify our envision.

\subsection{City-Level Comparison}

In this section, we will mainly discuss the relationship between the transportation development and labor migration. We focus on two cities that have great differences in transportation conditions, which are Shenzhen and Harbin. By comparing these two cities, we aim to reveal how transportation can contribute to the labor shift.

To measure the develop degree of the transportation system, we first generate the graph of freight traffic in Harbin and Shenzhen, respectively (Figure 1). From the graph, it is obvious that the transportation developments in the two cities have shown great divergence. Back to 1990, Harbin shew greater freight traffic than Shenzhen did, though the difference was small. In 1990, the freight traffic in Harbin was 1632.3; in Shenzhen, however, the freight transportation was only 1349 . In the following 25 years, Harbin didn't show any significant improvements in freight transportation; rather, it even seems to experience a slight decrease. However, the freight traffic in Shenzhen skyrocketed from 1349 in 1990 
to 32,475 in 2015 , which was more than 35 times that in Harbin.

The reason why we choose freight traffic to measure transportation development is that we can find the most valid data on this aspect. Passenger traffic can be somewhat biased because it may change violently as the population changes. Also, because Harbin is more than 25 times larger than Shenzhen, the mileage for each kind of transportation in two cities is also an inaccurate measurement. Moreover, restricted by the availability of the data, we are not able to use the turnover volume of freight traffic or turnover volume of passenger traffic as an effective measurement. Therefore, freight traffic is the most fitful measurement of transportation.

In the graph (Figure 2), we compare the changes in population in two cities from 1980 to 2015. In 1980, the population in Harbin was twenty-four times of that in Shenzhen (814.04 in Harbin and 33.29 in Shenzhen). After the 1990s, Shenzhen experienced accelerated growth in population, and its population gradually outnumbered the population in Harbin in 2010. In 2015, the difference in population between Harbin and Shenzhen was as large as 1.765 million people. The graph displays the population growth trend of each city clearly: Shenzhen has experienced fast and steady growth in population, while the population in Harbin didn't increase significantly; instead, it even had a noticeable decline in recent years.

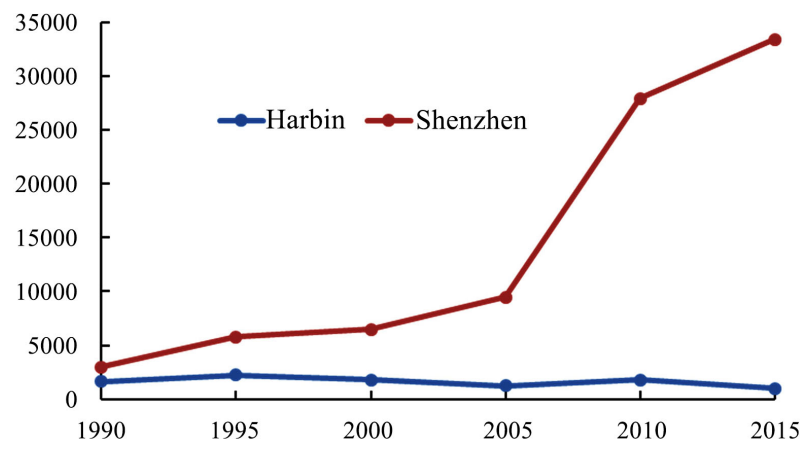

Figure 1. Comparison between the freight traffic in Harbin and Shenzhen (Unit: 10,000 tons) (source: Statistic Bureau of Shenzhen and the Government of Harbin).

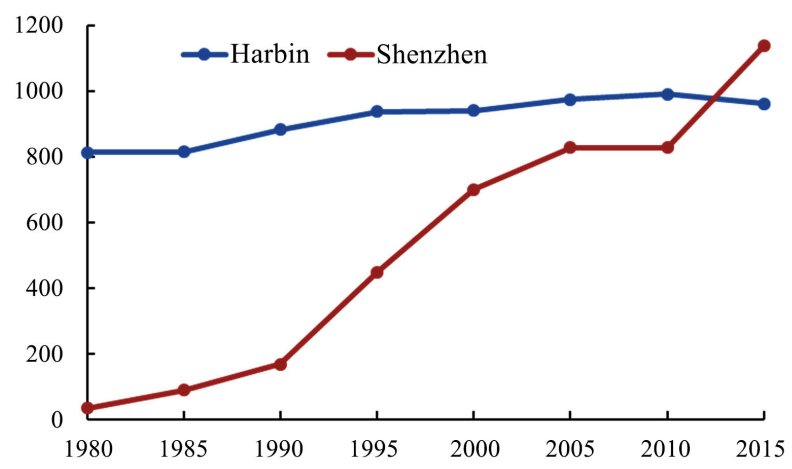

Figure 2. Comparison between the population in Harbin and Shenzhen (Unit: 10,000 persons) (source: Statistic Bureau of Shenzhen and the City of Harbin). 
Also, the paper considers the policy differences in these two cities. In 1980, the national policy was basically the same: the government started policies to reform state-owned enterprises and agriculture all across China. However, regional policies were different. China started its Reform and Opening in 1980, and Shenzhen was one of the special economic zones. Besides industry reformation, the policy also included the operation of harbors. The population started to grow since then and accelerated after opening several lager ports such as Yantian Port, Chiwan Port, and Mawan Port in 1994. In Harbin, on the other hand, the regional policy paid more attention to the industry reformation rather than transportation development. Thus, either transportation or population had a significant change there. Therefore, a causal relationship may exist between transportation development and labor distribution.

\subsection{National Comparison}

After a detailed observation of two specific cities, the paper will give a whole picture of the transportation development and labor distribution in China, and further develop the understanding of the relationship between the two factors.

Figure 3 shows the national transportation development in multiple dimensions. It depicts a tendency of convergence in transportation development. Main highways and railways mainly concentrate in the East, coastal areas, and some in Sichuan Basin (Figure 3(a)), and this phenomenon is more explicit in land (Figure 3(b) and Figure 3(c)) and water traffic (Figure 3(f) and Figure 3(g)) than in air traffic (Figure 3(d) and Figure 3(e)). Air transportation is relatively balanced distributed all around China, while the convergence is still noticeable [5].

Figure 4 mainly represents the population density across China in 2015. The densely populated areas are the eastern areas, coastal areas, and the Sichuan Basin, and they are separated from the less densely populated western and central areas by the "Hu Huanyong Line".

On the labor migration direction, the labor in the western and central parts of China move towards eastern and coastal areas where the transportation is better developed. People in the east and coastal areas tend to move within the area, and the scale of migration is much smaller than those in the western and central areas [6]. This phenomenon fits the expectation that people move to regions with more developed transportation systems.

This relationship might be causal if we combine with our discussion in 2.1. Moreover, from Figure 3 and Figure 4, the paper confirms that this kind of phenomenon can be nationwide.

\subsection{A Natural Experiment}

To understand the transportation's effects better, we conduct a case study in this Section.

The Kobe Earthquake in January 1995 in Japan is a perfect example of our study. According to FDMA (Frequency Division Multiple Access), the earthquake destroyed 7245 sections of roads, 330 bridges, numbers of subways, rail- 
ways, and bus operators (Fumio, 2012). Its population also declined by 1.23 percent, as Figure 5 shows.

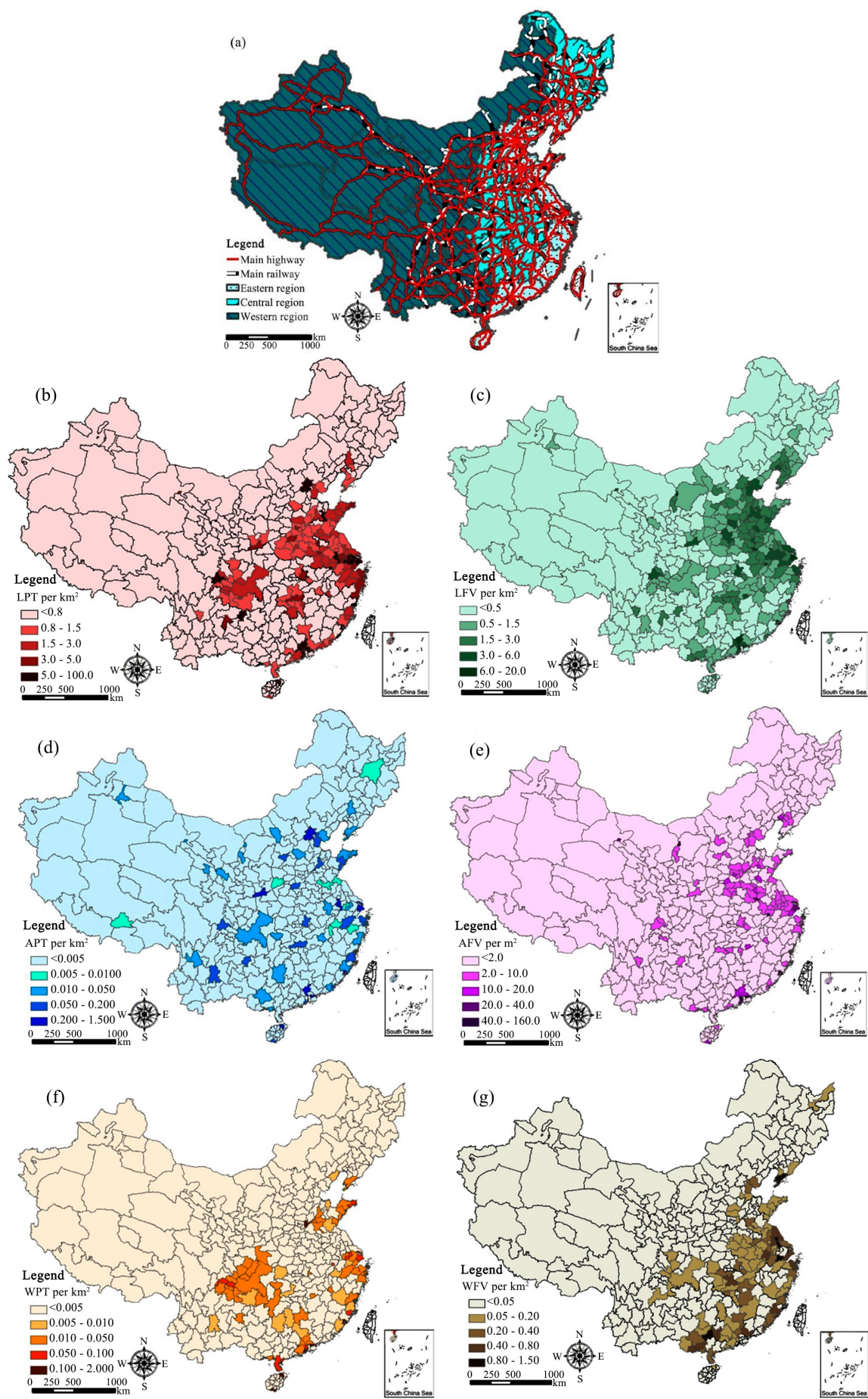

Figure 3. Cont. (a) Three regions and main land transport network in China; (b) Land passenger traffic; (c) Land freight volume; (d) Air passenger traffic; (e) Air freight volume; (f) Water passenger traffic; and (g) Water freight volumes. (source: Zhao, Jinbao, et al. "Examining the Association of Economic Development with Intercity Multimodal Transport Demand in China: A Focus on Spatial Autoregressive Analysis". ISPRS International Journal of Geo-Information). 


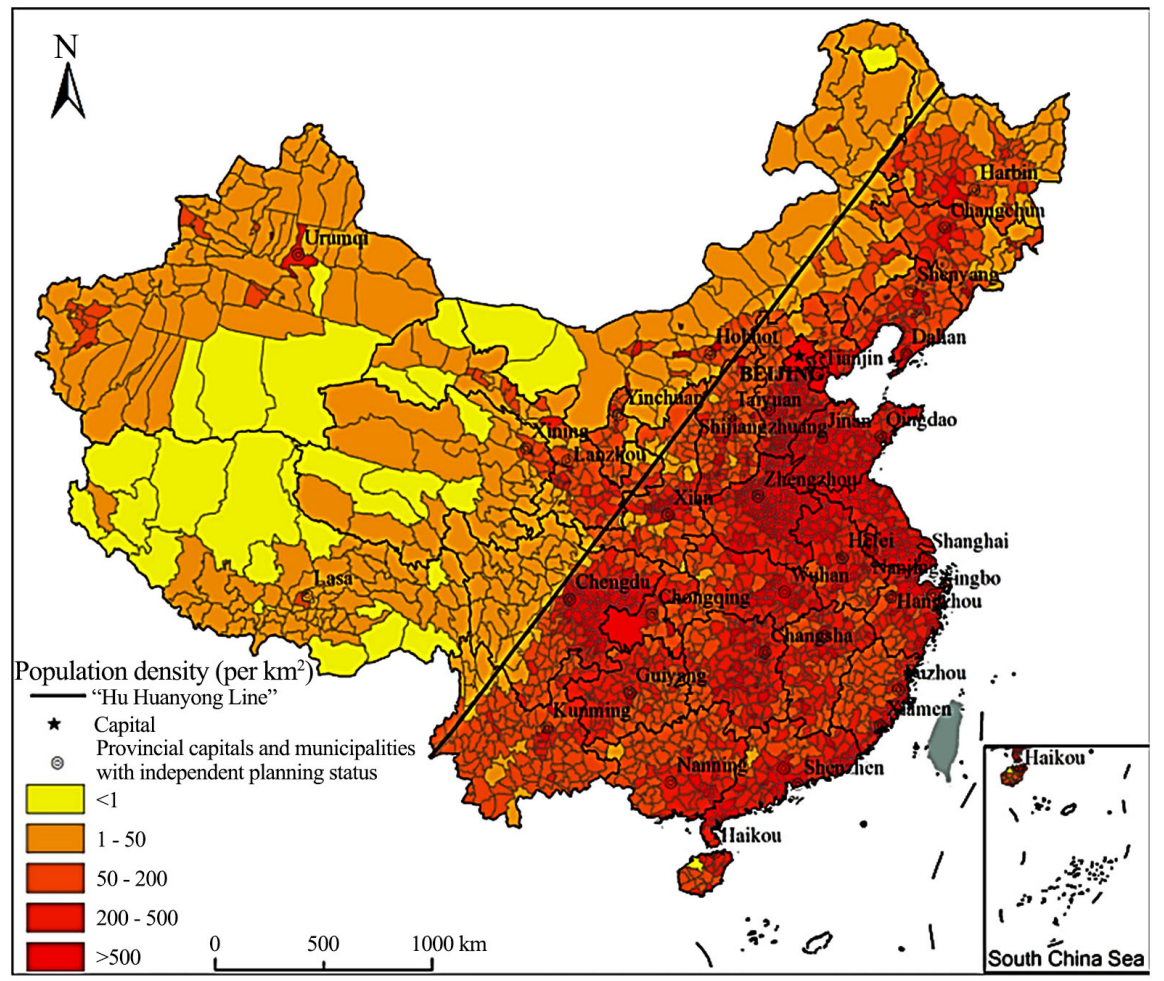

Figure 4. Population density in county level in China (2015) (source: Li, Minmin, et al. "Study on Population Distribution Pattern at the County Level of China". Sustainability).

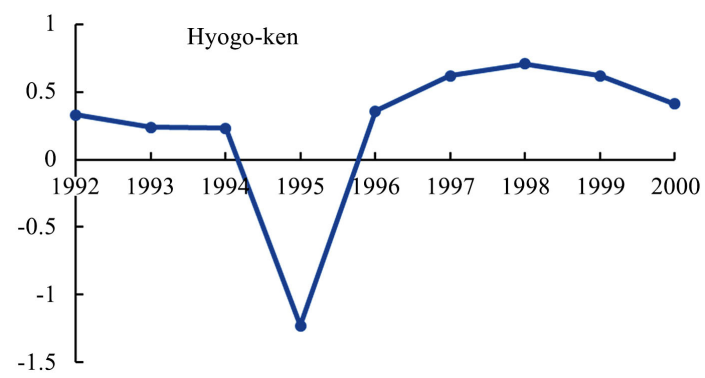

Figure 5. Percentage change in population in Hyogo-ken (1992-2000) (Unit: percent) (source: Statistic Bureau of Japan; Note: Kobe locates in Hyogo-ken).

In Figure 5, the population shew a greater growth rate in 1996 than in 1992-1994, and this trend continued until 2000. At the same time, Japan started its reconstruction projects called Phoenix HYOGO. This ten-year project had three elementary steps, and the first one that started from 1995 to 1997, called The Priority Three-Year Reconstruction Plan, focusing on the reconstruction of living quarters for the victims and transportation infrastructures such as roads, harbors, and railways [7].

The transportation damage caused by the earthquake was a shock to the city. Therefore, it is a favorable opportunity to study the effect of transportation construction alone. The transportation construction and population growth show high consistency, which can suggest a possible causality between transportation development and population distribution. 


\section{Labor Shift and Economic Growth}

After we testify that transportation could induce the labor shift, we attempt to prove that the labor shift could make contributions to economic growth. The methodology that we use is to compare Shenzhen and Harbin's GDP growth from 1980 to 2015 with population.

From Figure 2 that the paper mentioned, we can see the huge population discrepancies between two cities in 1980, but the outcome in 2015 was astonishing: the population in Shenzhen was 1765 thousand larger than that of Harbin. The population in Shenzhen has increased by 25 times in 35 years. However, the population in Harbin remained stable and even decreased from 2005 to 2015.

Since the discrepancies between Shenzhen and Harbin of the GDP in 2015 is so huge that we can't observe their GDP discrepancies in 1980 (as shown in Figure 6), so we adjust our figure to measure the log of Shenzhen's and Harbin's GDP. Figure 7 shows that as the population grew in Shenzhen, Shenzhen's GDP boosted from 2.7 billion in 1980 to 18,014 billion in 2015 . Undoubtedly, it is marvelous to improve the GDP for about 5000 times within 35 years. In contrast, Harbin's relatively stable and even decreasing trend results in its retard GDP growth and more profound labor shift.

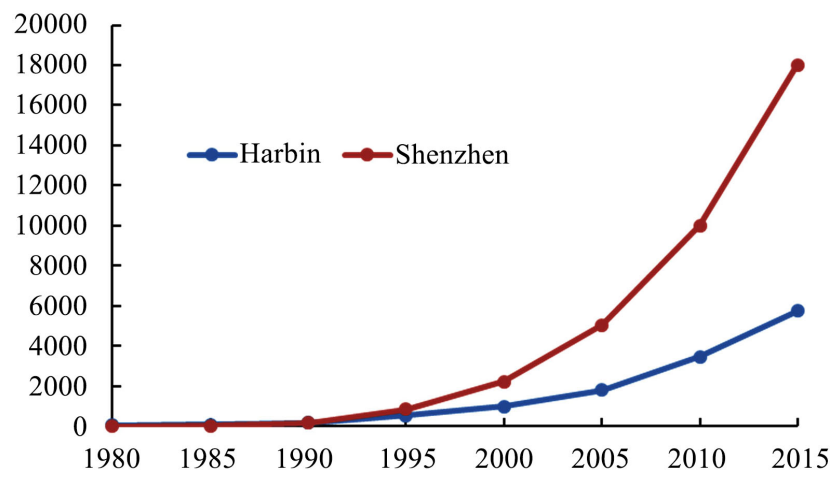

Figure 6. The GDP growth between Harbin and Shenzhen from 1980 to 2015 (Unit: billion) (source: Statistic Bureau of Shenzhen and the Government of Harbin).

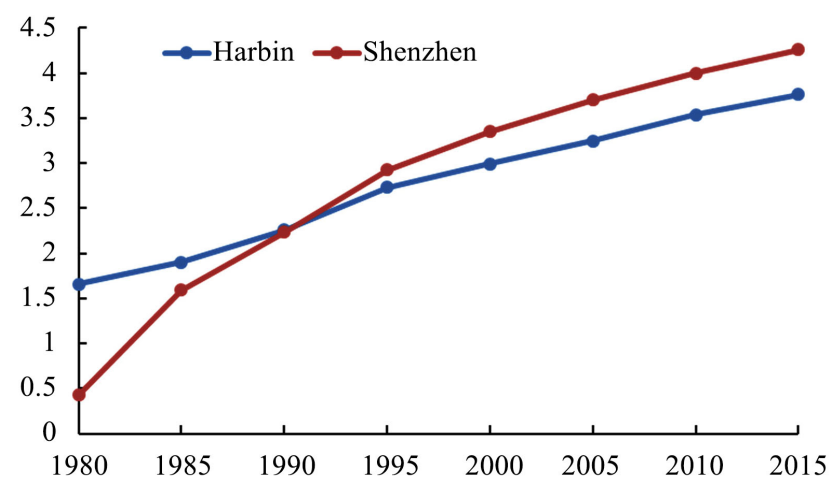

Figure 7. LOG of the GDP growth of Shenzhen and Harbin from 1980 to 2015 (source: Statistic Bureau of Shenzhen and the Government of Harbin). 


\section{Transportation and Labor Redistribution}

Our purpose is to prove that transportation could facilitate the redistribution of the population. Therefore, discussing the relationship between transportation and labor redistribution is necessary. So we employ two models which are effective to be the testimonies.

\subsection{TOD (Transportation Oriented Development)}

TOD is a model that redistributes the resources according to the pattern of transportation. For instance, infrastructures such as schools are built in the central part of the city. Thus, the population is larger in the central part of the city. The way TOD works is to build the new roads inside the cities, expand the scale of the city and stimulate these essential infrastructures to construct in these expanding areas. After the infrastructures redistribute corresponding to the development of the new roads, the population in the central part will decrease and spread to other parts of the city. Specifically, the concept of the TOD is using the overall pattern of transportation to balance volatile resources and population [8].

Thus, TOD provides us with an inspiration to population redistribution disseminating resources such as educational resources and some trade opportunities. Plus, TOD has the potential to be applied on any scale, inside a city, inter-cities, or even inter-countries.

\subsection{Intercity Transportation Development}

An effective transportation system between cities can also be an important way to help labor migrate. As former studies have shown, intercity transportation can propel the growth of less developed cities by providing access to the market in larger cities and the global market [3]. A more developed transportation system can drive down the cost of the transaction and commute. As a result, economic growth in the city can be accelerated and attract more labor [1]. Considering the researches that have done before, developing an effective transportation system between smaller cities and larger cities is a feasible way.

However, which kind of transportation that the government should choose to develop in different regions is an essential issue. Different regions may respond better to different kinds of transportation, which means a region may gain better growth by developing a certain kind of transportation. In the research done by Zhao Jinbao et al., they found that in the eastern region, land transportation contributes more to the regional growth; in the central part of China, water and air transportation have a stronger correlation to GDP growth; While in the western region, land and air transportation can be more effective [9]. This study can be instructive because it can help the government to decide which kind of transportation to invest in. Choosing the most effective intercity transportation form can not only boost the economy and attract labor most significantly, but it can also avoid the cost that arises because of wrong choices.

Therefore, by combining the TOD and intercity transportation system, the 
labor redistribution can be achieved. Transportation development does provide solutions to the problem caused by transportation.

\section{Conclusions}

The paper discusses the relations between transportation and labor redistribution. Based on the result in previous chapters, the paper proposes three feasible solutions, which are developing the transportation system, reallocating education resources, and setting up profitable firms.

1) Transportation development: The first solution is to develop transportation systems in these small cities that fall behind, and then utilize the TOD method, which is to rely on the transportation patterns to balance the volatile resources. As the paper has mentioned above, the intercity transportation system is also a feasible solution to the unbalanced labor distribution. Intercity transportation can make communication and transaction between larger and smaller cities easier, and this can bring profit to smaller cities and incentive their developments. Also, choosing the right form of the transportation system to develop between cities in different areas can spur regional development more effectively [5]. With accelerated development, more labor will be attracted back to smaller cities and ensure further development.

2) Education resources: Transportation development would facilitate population growth and attract talents at the same time. For instance, if a second-tier city establishes an airline which directly connects New York or other foreign big cities, it would attract foreign teachers to work in this city and enhance the children's overall average English level. Education improvement would attract more talents back to the second-tier city and bring huge economic growth.

3) Profitable firms: Undoubtedly, if we intend to redistribute the population in the big cities and stimulate these people back to relatively small cities, we need to provide opportunities in smaller cities. Profitable firms are the ones who provide these opportunities. Our solution is to construct intercity railroads, airlines, water lines, and highways first in the second-tier city. Then, we will suggest the government enact some policies which are favorable to the city such as lowering the tax rate. Undeniably, these policies would prompt more profitable firms to establish their headquarters there. Since the city has a developed transportation system, and the company can ensure its competitiveness, more and more firms would be attracted. Consequently, people will shift back to these cities.

\section{Further Consideration}

Our research excludes many other variables and studies the effect of transportation solely. Since none of the two cities in China experiences the same condition, possibly some other accidents may affect the overall data, such as the differences in climate, cultural backgrounds, natural disasters, and government policies. Undeniably, when discussing the effects of only one factor, changes in variables are inevitable, especially in the question we attempt to figure out in this paper. 
Thus, further researches are necessary. Future research can take more variables into account and then conclude if other factors can also influence labor emigration. Additionally, in the future, we will focus on means to facilitate the redistribution of the population other than transportation development as well.

\section{Acknowledgements}

Thanks for Professor David Parsley from Vanderbilt University who gave the paper vital and helpful instructions and advice. Thanks for Banerjee, Cervero, Robert, Li, Minmin, and Zhao Jinbao whose resources played a pivotal role in our essay, made giant contributions to the genesis of our methodology, and provided a platform for us to do city-level comparisons from the aspects of GDP, population growth rate, and transportation development level. It is the results from these people who inspired us and helped us to do research on what we want to reveal. We sincerely wish that their work can be useful for more and more people. Also thanks for CIS program which provided our paper financial aids and advice during the process of writing the paper.

\section{Conflicts of Interest}

The authors declare no conflicts of interest regarding the publication of this paper.

\section{References}

[1] Redding, S.J. and Turner, M.A. (2014) Transportation Costs and the Spatial Organization of Economic Activity. https://www.nber.org/papers/w20235

https://doi.org/10.3386/w20235

[2] Ahlfeldt, G.M., Redding, S.J., Sturm, D.M. and Wolf, N. (2014) The Economics of Density: Evidence from the Berlin Wall. https://www.nber.org/papers/w20354 https://doi.org/10.3386/w20354

[3] Banerjee, A., Duflo, E. and Qian, N. (2012) On the Road: Access to Transportation Infrastructure and Economic Growth in China. https://www.nber.org/papers/w17897 https://doi.org/10.3386/w17897

[4] Population of Internal Migration in China from 1982 to 2017 (n.d.). https://www.unicef.cn/figure-118-migrant-population-19822017

[5] Li, M., He, B., Guo, R., Li, Y., Chen, Y. and Fan, Y. (2018) Study on Population Distribution Pattern at the County Level of China. Sustainability, 10, 3598. https://doi.org/10.3390/su10103598

[6] World Bank (2009) World Development Report 2009: Reshaping Economic Geography. Washington.

[7] Ohtake, F., Okuyama, N., Sasaki, M. and Yasui, K. (2012) Impacts of the Great Hanshin-Awaji Earthquake on the Labor Market in the Disaster Areas. Japan Labor Review, 9, 42-63.

[8] Cervero, R., Ferrell, C. and Murphy, S. (2002) Transit-Oriented Development and Joint Development in the United States: A Literature Review. Transportation Research Board, National Research Council, Washington DC.

[9] Zhao, J.B., Guo, D., Wang, J., Yang, Z. and Zhang, H.F. (2018) Examining the Asso- 
ciation of Economic Development with Intercity Multimodal Transport Demand in China: A Focus on Spatial Autoregressive Analysis. ISPRS International Journal of Geo-Information, 7, 56. https://doi.org/10.3390/ijgi7020056 